
\title{
Resesarch Sulure \\ Detailed analysis of recovery process of cranial nerve palsy after IMRT-based comprehensive treatment in nasopharyngeal carcinoma
}

\author{
jian zang \\ Xijing Hospital \\ yan li \\ Xijing Hospital \\ shanquan luo \\ Xijing Hospital \\ jianhua wang \\ Xijing Hospital \\ bingxin hou \\ Xijing Hospital \\ min yao \\ UH Cleveland Medical Center \\ lina zhao \\ Xijing Hospital \\ mei shi ( $\square$ mshi82@hotmail.com ) \\ Xijing Hospital
}

\section{Research Article}

Keywords: cranial nerve palsy, IMRT, nasopharyngeal carcinoma, comprehensive treatment, recovery

Posted Date: April 21st, 2021

DOI: https://doi.org/10.21203/rs.3.rs-416076/v1

License: (c) (1) This work is licensed under a Creative Commons Attribution 4.0 International License. Read Full License 


\section{Abstract \\ Background}

cranial nerve $(\mathrm{CN})$ palsy in nasopharyngeal carcinoma with cancer-related involvement of cranial nerve has been considered as an unfavorable prognostic factor for NPC. We assessed the role of IMRT based treatment modality on the recovery of $\mathrm{CN}$ and investigated the prognostic value of $\mathrm{CN}$ palsy recovery.

\section{Methods}

A total of 115 NPC patients with CN palsy were included in the study. We referred CTCAE version 5.0 to evaluate the grade of $\mathrm{CN}$ palsy.

\section{Results}

All patients with grade $1 \mathrm{CN}$ palsy recovered completely during the 2 years of follow-up after definite treatment. Most grade 2 palsy could change gradually to grade 1 palsy or complete recovery during two years of follow-up. The 3-year DFS were $84.9 \%$ in patients experienced 1 or 2 symptom of CN palsy compared with $60.3 \%$ in patients with more than 2 symptoms of $\mathrm{CN}$ palsy (HR: $0.25,95 \% \mathrm{Cl}: 0.07-0.89, P$ $=0.001)$.

\section{Conclusions}

IMRT based comprehensive treatment could effectively promote the recovery of tumor-related CN palsy in locoregionally advanced NPC.

\section{Introduction}

Nasopharyngeal carcinoma (NPC) is a cancer arising from the nasopharyngeal mucosal lining, from where the tumor can invade adjacent anatomical organs. Hence, depending on the involvement of anatomical structures, the clinical symptoms varies considerably from person to person, including epistaxis, nasal obstruction, hearing impairments, headache and cranial nerve (CN) palsy. The incidence of CN palsy is approximate $8-12.4 \%$ in NPC[1]. CN palsy is classified as T4 stage according to the American Joint Committee on Cancer/Union for International Cancer Control (AJCC/UICC).It has been considered as an unfavorable prognostic factor for NPC patients[2, 3]. Several studies reported patients with complete recovery from $\mathrm{CN}$ palsy had better overall survival (OS) than these without complete recovery after receiving conventional radiation technique or 3-dimensional conformal radiation therapy (3D-CRT) based comprehensive treatment. Moreover, multiple CN palsy and long recovery duration were associated with poor OS[4,5]. Therefore, the recovery of $\mathrm{CN}$ palsy seems to predict a better survival 
outcome in before intensity modulated radiation therapy (IMRT) era. However, the detail of recovery process of $\mathrm{CN}$ palsy has not been investigated by these studies.

Undoubtedly, IMRT is a "Game-Changing" radiation technique for NPC due to the improved dosimetric properties. Locoregional control and survival have been improved by IMRT, and toxicity has been reduced[6, 7]. Compared with conventional radiotherapy and 3D-CRT, IMRT could improve the local control from 84.7-90.5\% for NPC[7].Induction chemotherapy followed by IMRT based concomitant chemoradiotherapy (IC + CCRT) and concomitant chemoradiotherapy (CCRT) are alternative treatment options for patients with CN palsy according to National Comprehensive Cancer Network (NCCN) guidelines and guidelines of Chinese Society of Clinical Oncology (CSCO). These treatment modalities result in more than $90 \%$ local control rate for locoregionally advanced NPC $[8,9]$. However, it is still unknown whether the superior local control rate could lead to a high relief rate of $\mathrm{CN}$ palsy with these treatment modalities. In this study, we investigate the recovery process of different symptoms of CN palsy, and explore the influence of treatment-related factors on the recovery of $\mathrm{CN}$ palsy and the prognostic value of $\mathrm{CN}$ palsy recovery in the era of IMRT. To our knowledge, this is the first study focus on the detailed recovery process of CN palsy in NPC patients receiving IMRT-based treatment modalities.

\section{Methods And Materials}

\section{Patients}

We reviewed the NPC database from cancer-specific database platform in XiJing Hospital between January 1, 2012 and December 31, 2016 and 514 patients with histologically proved nasopharyngeal squamous cell carcinoma treated with radiotherapy were identified. Of these patients, $121(22.4 \%)$ had $\mathrm{CN}$ palsy symptoms. Six patients were excluded: 2 received radiotherapy alone, 3 did not complete the treatment course, and 1 received palliative treatment. The remaining 115 NPC patients with CN palsy were included in the study. This retrospective review was approved by our institutional review board and was in accord with the Helsinki Declaration of 1975 as revised in 1983.

\section{Diagnosis and Evaluation}

The diagnosis of $\mathrm{CN}$ palsy depended on clinical symptoms physical examination, and magnetic resonance imaging (MRI) with or without thin slice computerized tomography imaging (CT) of skull base. Physical examinations were conducted by three radiation oncologists from pretreatment to the whole follow-up period. For patients with $\mathrm{CN}$ palsy symptoms but no imaging evidence, specialist consultation was conducted to exclude non-cancer related $\mathrm{CN}$ palsy. Two radiologists reviewed all the imaging records and disagreements were resolved by consents. Because of lack of criteria for $\mathrm{CN}$ palsy grade, we referred Common Terminology Criteria for Adverse Events (CTCAE) version 5.0 to evaluate the grade of CN palsy. Grade 1 palsy was defined as asymptomatic, clinical or diagnostic observation only and intervation not indicated. Grade 2 palsy was defined as moderate symptoms with limiting instrumental activities of daily living. Graded 3 palsy was defined as sever symptoms with limiting selfcare. 


\section{Treatment}

All patients were treated with definitive radiotherapy. The detail of radiotherapy process was described in our previous studies[10, 11]. In this study, 34 of 115 patients $(29.6 \%)$ received fixed-gantry IMRT technique, 81 (70.4\%) patients received volumetric modulated arc therapy (VMAT) technique.

Of these patients, 63 (54.8\%) were treated with IC followed by CCRT, and 52 patients (45.2\%) received CCRT alone. IC was administrated to patients with high risk metastatic lymph nodes, such as N2 to N3, extracapsular nodal spread, central nodal necrosis, $\geq 3 \mathrm{~cm}$ in greatest dimension, and nodal grouping metastasis in unilateral cervical. Patients with N0 or low risk N1 received CCRT alone. The induction chemotherapy included TP regimen (docetaxel $75 \mathrm{mg} / \mathrm{m}^{2}$, cisplatin $75 \mathrm{mg} / \mathrm{m}^{2}$ ), PF regimen (cisplatin 80 $\mathrm{mg} / \mathrm{m}^{2}$, 5-FU $800-1000 \mathrm{mg} / \mathrm{m}^{2}$ days 1 to 5), GP regimen (gemcitabine $1000 \mathrm{mg} / \mathrm{m}^{2}$, cisplatin 75 $\mathrm{mg} / \mathrm{m}^{2}$ ), and TPF regimen (docetaxel $75 \mathrm{mg} / \mathrm{m}^{2}$, cisplatin $75 \mathrm{mg} / \mathrm{m}^{2}, 5-\mathrm{FU} 750 \mathrm{mg} / \mathrm{m}^{2}$ days 1 to 5 ) given every 3 weeks for $2-3$ cycles. Concurrent chemotherapy consisted of cisplatin $\left(100 \mathrm{mg} / \mathrm{m}^{2}\right.$ every 3 weeks or $40 \mathrm{mg} / \mathrm{m}^{2}$ weekly).

\section{Definition and Statistical analysis}

Complete recovery was defined as complete disappearing of $\mathrm{CN}$ palsy symptoms. The follow up time was calculated from the date of treatment completion to either the date of death or the last review date. Patients were reexamined at least every 3 months in the first 2 years, then every 6 months for up to 5 years or until death. The grade of $\mathrm{CN}$ palsy symptoms was recorded in detail by two radiation oncologists. The survival endpoints included overall survival (OS), progression-free survival (PFS), distant metastasis-free survival (DMFS) and locoregional recurrence-free survival (LRFS). OS was measured from the date of treatment completion to death; PFS was measured from the date of treatment completion to the date of disease progression or death from any causes; DMFS was defined as the time from end of treatment to first detection of distant metastasis; LRFS was defined as the time from end of treatment to first detection of local or lymph node region relapse.

The variation of measurement data in groups were compared by means of Student's $t$ test, and data was presented as means \pm standard error of the mean (SEM) values. Differences in proportions between groups were evaluated by $x^{2}$ test. Numerical variable was transformed to categorical variable using median as cut-off if it was not Gaussian distribution, such as tumor volume. The Kaplan-Meier method was used to estimate the endpoints, survival curves were compared using the log-rank test. Cox proportional hazard model was used to identify potentially independent prognostic factors, and the proportional hazards assumption was tested with Schoenfeld residuals. The hazard ratio (HR) and its $95 \%$ confidence interval $(95 \% \mathrm{Cl})$ were used to indicate the prognostic value of risk factors. A two-sided $p$ value of less than 0.05 was considered significant.

\section{Results}




\section{Patient characteristics and incidence of CN palsy}

Patient characteristics are summarized in Table 1. The male/female ratio was 3.8:1. Median age was 49 years (range, $18-83$ years); $83.5 \%$ patient ages were less than 60 years. Most patients $(77.4 \%)$ had regionally metastatic lymph nodes at the time of diagnosis of NPC. as All patients had non-keratinizing squamous cell carcinoma. Sixty-three patients $(54.8 \%)$ received induction chemotherapy. The median radiation dose was $72.62 \mathrm{~Gy}$.

Trigeminal nerve (TN, CN V) disorder was the most common CN palsy symptom ( $90.4 \%)$, followed by abducens nerve ( $\mathrm{AN}, \mathrm{CV} \mathrm{VI})$ disorder (36.5\%), oculomotor nerve (ON, CN III) disorder (22.6\%), hypoglossalnever (HN, CN XII) disorder (6.1\%) and facial nervenerve (FN, CN VII) disorder (3.5\%). Of all patients, 68 patients (59.1\%) had one symptom of CN palsy, 30 patients $(26.1 \%)$ had two symptoms of $\mathrm{CN}$ palsy and 17 patients (14.8\%) had more than three symptoms of $\mathrm{CN}$ palsy. Because the incidences of $\mathrm{HN}$ disorder and FN disorder were very low, we just focused on the recovery of TN disorder, AN disorder and ON disorder in this study.

\section{Correlation between duration of $\mathrm{CN}$ palsy and symptom grade}

According to the grade definition of $\mathrm{CN}$ palsy, no patients had grade 3 symptom in this cohort. Patients with grade $2 \mathrm{CN}$ palsy had significantly longer duration of symptom before clinical diagnosis. The mean duration time were $4.22 \pm 0.29$ months vs. $1.32 \pm 0.19$ months between patients with grade 2 and grade 1 TN disorder, $3.72 \pm 0.41$ months vs. $1.86 \pm 0.37$ months between grade 2 and grade 1 AN disorder, $3.14 \pm 0.57$ months vs. $1.41 \pm 0.35$ months between grade 2 and grade $1 \mathrm{ON}$ disorder, with significantly statistical differences (Fig. 1).

\section{Evaluation of recovery process of $\mathrm{CN}$ palsy}

In general, the palsy severity of $\mathrm{TN}, \mathrm{AN}$ and $\mathrm{ON}$ were reducing gradually after completion of treatment. During the two years of follow-up, the proportion of patients with any grade of TN, AN, and ON palsy decreased from $90.4 \%$ to $20 \%, 36.5 \%$ to $8.3 \%$, and $22.6 \%$ to $5 \%$, respectively. The rate of complete recovery of $\mathrm{TN}, \mathrm{AN}$, and $\mathrm{ON}$ palsy were $77.9 \%, 77.2 \%$ and $77.8 \%$ during the two-years follow-up (Fig. S1). The grade of $\mathrm{CN}$ palsy before treatment had an impact on the recovery of $\mathrm{CN}$ symptom. All patients with grade $1 \mathrm{CN}$ palsy recovered completely during the 2 years of follow-up after definite treatment (Fig. 2a-c). Most grade $2 \mathrm{TN}, \mathrm{AN}$ and $\mathrm{ON}$ palsy could change gradually to grade 1 palsy or complete recovery during two years of follow-up (Fig. 2d-f). The complete recovery rate of grade $2 \mathrm{TN}, \mathrm{AN}$, and ON palsy were $67.5 \%, 58.8 \%$, and $61.1 \%$, respectively. However, there were still a small percentage of patients who had persistent grade 2 TN (13.3\%), AN (13.8\%), and ON (6.6\%) palsy (Figure 2d-f).

\section{Influence of treatment-related factors on complete recovery of CN palsy}

Treatment-related factors associated with complete recovery of $\mathrm{CN}$ palsy were explored including radiation doses and different treatment modalities. Using median radiation dose (72.62 Gy) as dichotomy, there were no differences of complete recovery rates of TN palsy and ON palsy (Fig. 3a,c). 
However, for AN palsy, patients received higher radiation dose (>72.62Gy) had higher complete recovery rate than those received lower radiation dose $(\leq 72.62 \mathrm{~Gy})$, with significantly statistical differences between two groups in 12 months (28.3\% vs. $51.2 \%)$ and 18 months (14.2\% vs. $38.3 \%)$ after treatment ((Fig. 3b).

There were no significant differences in complete recovery rates of CN palsy and AN palsy between patients treated with IC+CCRT versus CCRT. Compared with CCRT, IC+CCRT had a trend to improve the recovery rate of AN palsy, but not reached significant difference (Figure 3d-f).

\section{Prognostic value of CN palsy}

The median follow-up was 48 months (range: 7-109 months). For the whole cohort, the 3-year and 4-year DFS, OS, DMFS and LRFS were $80.9 \%, 88 \%, 89.4 \%, 97.1 \%$ and $78.6 \%, 84 \%, 88.2 \%, 94.4 \%$, respectively.

In order to clarify the prognostic value of $\mathrm{CN}$ palsy, patients were divided into two groups according to the number of $\mathrm{CN}$ palsy symptoms they experienced before treatment. Group 1 included patients experienced 1 or 2 symptoms of CN palsy, and patients in group 2 had more than 2 symptoms of CN palsy. The 3-year DFS were $84.9 \%$ in group 1 compared with $60.3 \%$ in group 2 (HR: $0.25,95 \% \mathrm{Cl}: 0.07-0.89, P=0.001$ ). Patients in group 1 had a trend in achieving a better 3-year OS compared with those in group 2, but without statistically significant differences (89.4\% vs. 78.4\%; HR: $0.21,95 \% \mathrm{Cl}: 0.06-1.26, P=0.095)$. Patients in group 1 had significantly better 3-year DMFS than those in group 2 (92.1\% vs. $71.8 \%$; HR: 0.12 , $95 \% \mathrm{Cl}: 0.02-0.73, P=0.02$ )(Fig. 4a-c). Nevertheless, there were similar 3-year LRFS between two groups (97.6\% vs. 94.7\%, HR: 0.21, 95\%Cl: 0.02-2.09, $P=0.148$ ) (Fig. 4d).

The prognostic value of pretreatment duration of $\mathrm{CN}$ palsy was analyzed in different types of $\mathrm{CN}$ palsy. A significant differences was observed for DFS $(P=0.046)$ in patients with pretreatment duration within 2 months of TN palsy compared with those with longer than 2 months(Fig. S2a), but no significant differences were observed for OS $(P=0.252)$, DMFS $(P=0.09)$ and LRFS $(P=0.052)$ between two groups (Fig. S2b-d). Prognostic value of pretreatment duration of AN and ON palsy were not detected for every survival endpoints (Fig. S3-4). There were no significant differences for PFS, OS, DMFS and LRFS between patients with complete recovery and non-complete recovery from $\mathrm{CN}$ palsy after receiving IMRT based comprehensive treatment (Fig. S5)

Multivariate analysis was performed to evaluate the potential prognostic factors for every endpoints. Factors included sex, age ( $\leq 50$ years vs. $\$ 50$ years), $\mathrm{N}$ stage (N0-1 vs. N2-3), histological type, treatment modalities, radiation dose ( $\leq 72.62 \mathrm{~Gy}$ vs. $872.62 \mathrm{~Gy})$, tumor volume $(\leq 55.5 \mathrm{ml}$ vs. $\otimes 55.5 \mathrm{ml})$, and number of $\mathrm{CN}$ palsy symptom ( $\leq 2$ symptoms vs. $\otimes 2$ symptoms). $\mathrm{N}$ stage and number of $\mathrm{CN}$ palsy symptom were positive prognostic factors for DFS ( $\mathrm{N}$ stage, HR: 2.93, 95\% Cl:1.16-7.38, $P=0.023$; number of CN palsy symptom, HR:2.53, 95\%Cl:1.05-6.1, $P=0.038$ ). Only $\mathrm{N}$ stage was an independent prognostic factor for OS (HR: $5.71,95 \% \mathrm{Cl}: 1.64-19.88, \mathrm{P}=0.006$ ). Although number of $\mathrm{CN}$ palsy symptom was close to positive correlation for DMFS, no significant differences were found on the multivariate analysis. For LRFS, multivariate analysis failed to detect any positive prognostic factor (Table 2). 


\section{Discussion}

$\mathrm{CN}$ palsy due to tumor infiltration of cranial nerve implies the locally extensive lesion in NPC. According to the $8^{\text {th }}$ edition AJCC staging system, CN palsy is classified as T4 disease. In the era of conventional radiotherapy and 3D-CRT, several studies reported number of CN palsy, palsy duration before treatment, recovery duration of palsy and complete recovery of $\mathrm{CN}$ palsy were associated with prognosis of patients with locoregionally advanced NPC [4, 5]. But there were lack of detailed information about the recovery process of $\mathrm{CN}$ palsy. This is the first study focus on the recovery process of $\mathrm{CN}$ palsy in patients received IMRT based definitive treatment.

Consistent with previous study, we found the most common $\mathrm{CN}$ palsy were trigeminal nerve palsy (90.4\%), adbucens nerve palsy (36.5\%), and oculomotor nerve palsy (22.6\%) in local advanced NPC[12]. We found that the longer duration of symptom was associated with the more severe symptoms, indicating more damage to the nerve. In this study, up to $77 \%$ of patients with TN, AN, or OS palsy could completely recovered within two years after treatment, indicating the efficacy of IMRT in complete recovery of upper CN palsy in NPC. AN and ON palsy in NPC were often due to intracranial involvement of tumor, such as involvement of cavernous sinus. Compared to IMRT, it was difficult to precisely deliver radiation dose to this area using conventional or 3D-CRT technique. IMRT has been shown to be associated with better 5-years local control compared with conventional RT and 3D-CRT[7, 13-15]. Therefore, the recovery of AN and ON palsy might result from tumor ablation by IMRT. The recovery of HN and FN palsy were not investigated in this study due to low incidence of these symptoms. So it was still unclear whether IMRT could lead to better recovery rate for the two types of palsy compared with conventional or 3D-CRT technique.

We showed that the pretreatment grade of $\mathrm{CN}$ palsy was significantly associated with recovery process of $\mathrm{CN}$ palsy. All grade 1 palsy achieved complete recovery within two years after treatment. However, only $70 \%$ of patients with grade 2 palsy had complete recovery, although all of them had some improvement. The radical radiation dose of NPC was routinely up to 70Gy in the tumor target for patients received IMRT $[16,17]$. Even complete response was achieved after induction chemotherapy, the dose of radiotherapy was still up to more than $66 \mathrm{~Gy}$ in the target of primary tumor and lymph nodes[18]. In this study, the radiation dose, using median dose as dichotomy, was not associated with the recovery of TN and ON palsy. But for AN palsy, the recovery rate was much higher in patients received higher than 72.62 Gy. Recently, IC followed by CCRT was confirmed to be a more effective regimen than CCRT alone for locoregionally advanced NPC. The 3 -year OS was improved by $5 \%$ with IC+CCRT $[8,9]$. Therefore, we compared the recovery of $\mathrm{CN}$ palsy in patients treated with IC+CCRT to those treated with CCRT. We found that except for recovery of AN palsy in which IC+CCTRT had a trend to improve recovery, there were no significant correlation between recovery of $\mathrm{CN}$ palsy and treatment regimens. These results implied AN palsy might be relieved more easily in NPC patients after IMRT based comprehensive modality.

Previous study reported multiple $\mathrm{CN}$ palsy and long duration of pretreatment symptom were worse prognostic factors for OS in locoregionally advanced NPC in the era of conventional radiotherapy[5]. In 
this study, we found patients with more than 2 symptoms of CN palsy had worse prognosis for DMFS but not for OS. Several previous studies suggested that intracranial involvement of NPC might be potential routes for hematogenous dissemination due to anatomically rich venous plexus[19, 20]. In this study, $75 \%$ of patients with more than 2 symptoms of $\mathrm{CN}$ palsy had intracranial involvement (data was not shown), which may contribute to a higher risk of distant metastasis. Except the pretreatment duration of TN palsy was a prognostic factor for DFS and had potential predictive role to impact on the OS, the prognostic value of pretreatment duration of $\mathrm{AN}$ and $\mathrm{ON}$ were still unclear due to small sample size. Different from previous studies, we did not find prognostic value of complete recovery of $\mathrm{CN}$ palsy in this study. Advances in radiation technique and comprehensive treatment modalities might weaken the prognostic role of complete recovery for survival.

In multivariate analysis, consistent with previous studies, $\mathrm{N}$ stage was found to be a significant prognostic factor for DFS and OS. Interestingly, the number of CN palsy was an independently prognostic factor for DFS after adjusting tumor-related factors, such as $\mathrm{N}$ stage, histological type and tumor volume. It is possible the number of $\mathrm{CN}$ palsy was associated with tumor volume which directly impacts the prognosis of locoregionally advanced NPC[21, 22]. However, we could not find association of tumor volume with the number of CN palsy in this study (Fig. S6), indicating tumor volume not necessary related to the extent of $\mathrm{CN}$ involvement in locoregionally advanced NPC.

\section{Conclusions}

IMRT based comprehensive treatment could effectively promote the recovery of tumor-related CN palsy in locoregionally advanced NPC, especially for the trigeminal nerve palsy, abducens nerve palsy, and oculomotor nerve palsy. Patients with more than 2 symptoms of $\mathrm{CN}$ palsy is a poor prognostic factor for disease-free survival.

\section{Abbreviations}

NPC:Nasopharyngeal carcinoma;CN:Cranial nerve;AJCC/UICC:American Joint Committee on Cancer/Union for International Cancer Control;OS:Overall survival;3D-CRT:3-dimensional conformal radiation therapy;IMRT:Intensity modulated radiation therapy;IC+CCRT:Induction chemotherapy followed by IMRT based concomitant chemoradiotherapy;CCRT:concomitant chemoradiotherapy;NCCN:National Comprehensive Cancer Network;CSCO:Chinese Society of Clinical Oncology;MRI:Magnetic resonance imaging;CT:computerized tomography imaging;CTCAE:Common Terminology Criteria for Adverse Events;VMAT:Volumetric modulated arc therapy;PFS;Progression-free survival;DMFS:Distant metastasisfree survival;LRFS:Iocoregional recurrence-free survival;SEM:Standard error of the mean;HR:Hazard ratio;TN:Trigeminal nerve;AN:Abducens nerve;ON:Oculomotor nerve;HN:Hypoglossalnever;FN: facial nerve.

\section{Declarations}




\section{Acknowledgements}

Not applicable.

\section{Authors' contributions}

Specific author contributions: mei shi, lina zhao, Jian zang, yan li, shanquan luo, jianhua wang, bingxin hou, min yao contributed to the design of the study, interpretation of the data, and critical revision of the manuscript. Jian zang, shanquan luo,yan li contributed to the collection of data,mei shi, lina zhao, Jian zang, min yao contributed to the diagnosis evaluation of nerve palsy. mei shi, lina zhao, Jian zang, shanquan luo, jianhua wang contributed to the analysis and interpretation of the data. Jian zang, yan li drafted the manuscript. All authors approved the final version of the manuscript for submission.

\section{Funding}

No funding was received for this study.

\section{Declarations}

\section{Ethics approval and consent to participate}

The trial was carried out in accordance with the principles of the Declaration of Helsinki.

\section{Consent for publication}

All authors have agreed to publish this manuscript.

\section{Availability of data and materials}

All original data will be made available upon request.

\section{Competing interests}

The authors declare that they have no competing interests.

\section{References}

1. Cheng SH, Tsai SY, Horng CF, Yen KL, Jian JJ, Chan KY, Lin CY, Terng SD, Tsou MH, Chu NM, Chen $\mathrm{HH}$, Chen PL, Chung YL, Hsieh Cl, Tan TD, Huang AT. A prognostic scoring system for locoregional control in nasopharyngeal carcinoma following conformal radiotherapy. Int $\mathrm{J}$ Radiat Oncol Biol Phys.2006;66: 992-1003.

2. Pan JJ, Ng WT, Zong JF, Chan LL, O'Sullivan B, Lin SJ, Sze HC, Chen YB, Choi HC, Guo QJ, Kan WK, Xiao YP, Wei X, Le QT, Glastonbury CM, Colevas AD, Weber RS, Shah JP, Lee AW. Proposal for the 8th edition of the AJCC/UICC staging system for nasopharyngeal cancer in the era of intensitymodulated radiotherapy. Cancer.2016;122: 546-558. 
3. Wu LR, Zhang XM, Xie XD, Lu Y, Wu JF, He X. Validation of the 8th edition of AJCC/UICC staging system for nasopharyngeal carcinoma: Results from a non-endemic cohort with 10-year follow-up. Oral Oncol.2019;98: 141-146.

4. Huang CC, Fang FM, Chen HC, Hsu HC, Huang TL, Su YL, Chang YC. Therapeutic outcome of nasopharyngeal carcinoma with cranial nerve palsy: a single institution experience of 104 patients. Onco Targets Ther.2017;10: 2069-2075.

5. Mo HY, Sun R, Sun J, Zhang Q, Huang WJ, Li YX, Yang J, Mai HQ. Prognostic value of pretreatment and recovery duration of cranial nerve palsy in nasopharyngeal carcinoma. Radiat Oncol.2012;7: 149.

6. Du T, Xiao J, Qiu Z, Wu K. The effectiveness of intensity-modulated radiation therapy versus 2D-RT for the treatment of nasopharyngeal carcinoma: A systematic review and meta-analysis. PLoS One.2019;14: e0219611.

7. Peng G, Wang T, Yang KY, Zhang S, Zhang T, Li Q, Han J, Wu G. A prospective, randomized study comparing outcomes and toxicities of intensity-modulated radiotherapy vs. conventional twodimensional radiotherapy for the treatment of nasopharyngeal carcinoma. Radiother Oncol.2012;104: 286-293.

8. Zhang Y, Chen L, Hu GQ, Zhang N, Zhu XD, Yang KY, Jin F, Shi M, Chen YP, Hu WH, Cheng ZB, Wang SY, Tian Y, Wang XC, Sun Y, Li JG, Li WF, Li YH, Tang LL, Mao YP, Zhou GQ, Sun R, Liu X, Guo R, Long GX, Liang SQ, Li L, Huang J, Long JH, Zang J, Liu QD, Zou L, Su QF, Zheng BM, Xiao Y, Guo Y, Han F, Mo HY, Lv JW, Du XJ, Xu C, Liu N, Li YQ, Chua MLK, Xie FY, Sun Y, Ma J. Gemcitabine and Cisplatin Induction Chemotherapy in Nasopharyngeal Carcinoma. N Engl J Med.2019;381: 1124-1135.

9. Sun Y, Li WF, Chen NY, Zhang N, Hu GQ, Xie FY, Sun Y, Chen XZ, Li JG, Zhu XD, Hu CS, Xu XY, Chen YY, Hu WH, Guo L, Mo HY, Chen L, Mao YP, Sun R, Ai P, Liang SB, Long GX, Zheng BM, Feng XL, Gong XC, Li L, Shen CY, Xu JY, Guo Y, Chen YM, Zhang F, Lin L, Tang LL, Liu MZ, Ma J. Induction chemotherapy plus concurrent chemoradiotherapy versus concurrent chemoradiotherapy alone in locoregionally advanced nasopharyngeal carcinoma: a phase 3, multicentre, randomised controlled trial. Lancet Oncol.2016;17: 1509-1520.

10. Zang J, Li C, Zhao LN, Wang JH, Xu M, Luo SQ, Hitchcock YJ, Shi M. Prognostic Model of Death and Distant Metastasis for Nasopharyngeal Carcinoma Patients Receiving 3DCRT/IMRT in Nonendemic Area of China. Medicine (Baltimore).2016;95: e3794.

11. Zang J, Li C, Xu M, Xu W, Kang X, Wang J, Luo S, Shi M. Induction chemotherapy followed by concurrent chemoradiotherapy is benefit for advanced stage nasopharyngeal carcinoma with different nonkeratinizing carcinoma subtypes. Sci Rep.2018;8: 13318.

12. Chen YP, Chan ATC, Le QT, Blanchard P, Sun Y, Ma J. Nasopharyngeal carcinoma. Lancet.2019;394: 64-80.

13. Pow EH, Kwong DL, McMillan AS, Wong MC, Sham JS, Leung LH, Leung WK. Xerostomia and quality of life after intensity-modulated radiotherapy vs. conventional radiotherapy for early-stage 
nasopharyngeal carcinoma: initial report on a randomized controlled clinical trial. Int J Radiat Oncol Biol Phys.2006;66: 981-991.

14. Zhang B, Mo Z, Du W, Wang Y, Liu L, Wei Y. Intensity-modulated radiation therapy versus 2D-RT or 3DCRT for the treatment of nasopharyngeal carcinoma: A systematic review and meta-analysis. Oral Oncol.2015;51: 1041-1046.

15. Liao JF, Ma L, Du XJ, Lan M, Guo Y, Zheng L, Xia YF, Luo W. Prognostic Value of Cavernous Sinus Invasion in Patients with Nasopharyngeal Carcinoma Treated with Intensity-Modulated Radiotherapy. PLoS One.2016;11: e0146787.

16. McDowell LJ, Rock K, Xu W, Chan B, Waldron J, Lu L, Ezzat S, Pothier D, Bernstein LJ, So N, Huang SH, Giuliani M, Hope A, O'Sullivan B, Bratman SV, Cho J, Kim J, Jang R, Bayley A, Ringash J. LongTerm Late Toxicity, Quality of Life, and Emotional Distress in Patients With Nasopharyngeal Carcinoma Treated With Intensity Modulated Radiation Therapy. Int J Radiat Oncol Biol Phys.2018;102: 340-352.

17. Gupta T, Sinha S, Ghosh-Laskar S, Budrukkar A, Mummudi N, Swain M, Phurailatpam R, Prabhash K, Agarwal JP. Intensity-modulated radiation therapy versus three-dimensional conformal radiotherapy in head and neck squamous cell carcinoma: long-term and mature outcomes of a prospective randomized trial. Radiat Oncol.2020;15: 218.

18. Zhao C, Miao JJ, Hua YJ, Wang L, Han F, Lu LX, Xiao WW, Wu HJ, Zhu MY, Huang SM, Lin CG, Deng $\mathrm{XW}$, Xie CH. Locoregional Control and Mild Late Toxicity After Reducing Target Volumes and Radiation Doses in Patients With Locoregionally Advanced Nasopharyngeal Carcinoma Treated With Induction Chemotherapy (IC) Followed by Concurrent Chemoradiotherapy: 10-Year Results of a Phase 2 Study. Int J Radiat Oncol Biol Phys.2019;104: 836-844.

19. Cao C, Luo J, Gao L, Yi J, Huang X, Li S, Xiao J, Zhang Z, Xu G. Magnetic Resonance ImagingDetected Intracranial Extension in the T4 Classification Nasopharyngeal Carcinoma with IntensityModulated Radiotherapy. Cancer Res Treat.2017;49: 518-525.

20. Chen L, Liu LZ, Chen M, Li WF, Yin WJ, Lin AH, Sun Y, Li L, Ma J. Prognostic value of subclassification using MRI in the t4 classification nasopharyngeal carcinoma intensity-modulated radiotherapy treatment. Int J Radiat Oncol Biol Phys.2012;84: 196-202.

21. Chen FP, Wen DW, Li F, Lin L, Kou J, Zheng WH, Li L, Zhou GQ, Sun Y. The Role of Post-Neoadjuvant Chemotherapy Tumor Volume for Prognostication and Treatment Guidance in Loco-Regionally Advanced Nasopharyngeal Carcinoma. Cancers (Basel).2019;11.

22. Li JY, Huang CL, Luo WJ, Zhang Y, Tang LL, Peng H, Sun Y, Chen YP, Ma J. An integrated model of the gross tumor volume of cervical lymph nodes and pretreatment plasma Epstein-Barr virus DNA predicts survival of nasopharyngeal carcinoma in the intensity-modulated radiotherapy era: a bigdata intelligence platform-based analysis. Ther Adv Med Oncol.2019;11: 1758835919877729.

\section{Tables}

Table 1 clinical characteristics of 115 patients with CN palsy 


\begin{tabular}{|c|c|}
\hline Characteristics & $\mathrm{N}(\%)$ \\
\hline Sex & \\
\hline $\begin{array}{c}\text { Male } \\
\text { Female }\end{array}$ & $\begin{array}{l}91(79.1) \\
24(20.9)\end{array}$ \\
\hline Age & Median: 49 years (range: $18-83$ years) \\
\hline N stage & \\
\hline N0 & $26(22.6)$ \\
\hline N1 & $49(42.6)$ \\
\hline N2 & $35(30.4)$ \\
\hline N3 & $5(4.4)$ \\
\hline Histological type & \\
\hline Nonkeratinising differentiated & $37(32.2)$ \\
\hline Nonkeratinising undifferentiated & $78(67.8)$ \\
\hline Treatment regimen & \\
\hline $\mathrm{IC}+\mathrm{CCRT}$ & $63(54.8)$ \\
\hline CCRT & $52(45.2)$ \\
\hline Radiation dose & Median: 72.62 Gy (range: 67.2-78.8 Gy) \\
\hline$\leq 72.62 \mathrm{~Gy}$ & $57(49.6)$ \\
\hline ૧72.62 Gy & $58(50.4)$ \\
\hline Tumor volume of primary tumor & Median: $55.5 \mathrm{ml}$ (range: $4.11-232 \mathrm{ml}$ ) \\
\hline$\leq 55.5 \mathrm{ml}$ & $58(50.4)$ \\
\hline $055.5 \mathrm{ml}$ & $57(49.6)$ \\
\hline CN palsy symptom & \\
\hline Trigeminal nerve disorder & $104(90.4)$ \\
\hline Abducens nerve disorder & $42(36.5)$ \\
\hline Oculomotor nerve disorder & $26(22.6)$ \\
\hline Hypoglossal never disorder & $7(6.1)$ \\
\hline Facial nerve disorder & $4(3.5)$ \\
\hline
\end{tabular}

IC+CCRT, induction chemotherapy followed by concurrent chemoradiotherapy; CCRT, concurrent chemoradiotherapy; $\mathrm{CN}$, cranial nerve

Table 2 multivariate analysis of prognostic factors 


\begin{tabular}{|c|c|c|c|}
\hline \multicolumn{4}{|l|}{ Disease-free survival } \\
\hline Factors & $\overline{\mathrm{HR}}$ & $95 \%$ CI & $P$ value \\
\hline Sex & 1.49 & $0.42-5.26$ & 0.537 \\
\hline Age & 1.67 & $0.68-4.06$ & 0.26 \\
\hline N stage & 2.93 & $1.16-7.38$ & $0.023 *$ \\
\hline Histological type & 2.79 & $0.91-8.56$ & 0.073 \\
\hline Treatment & 1.03 & $0.41-2.56$ & 0.955 \\
\hline Radiation dose & 1.29 & $0.53-3.17$ & 0.565 \\
\hline Tumor volume & 1.89 & $0.76-4.65$ & 0.168 \\
\hline Number of CN palsy symptom & 2.53 & $1.05-6.1$ & 0.038* \\
\hline \multicolumn{4}{|l|}{ Overall survival } \\
\hline Factors & HR & $95 \% \mathrm{CI}$ & $P$ value \\
\hline Sex & 0.65 & $0.16-2.64$ & 0.549 \\
\hline Age & 2.98 & $0.97-9.13$ & 0.056 \\
\hline N stage & 5.71 & $1.64-19.88$ & $0.006 *$ \\
\hline Histological type & 2.29 & $0.7-7.47$ & 0.17 \\
\hline Treatment & 2.45 & $0.81-7.4$ & 0.11 \\
\hline Radiation dose & 1.14 & $0.38-8.77$ & 0.816 \\
\hline Tumor volume & 2.81 & 0.89-8.77 & 0.076 \\
\hline Number of CN palsy symptom & 1.33 & $0.42-4.17$ & 0.626 \\
\hline \multicolumn{4}{|l|}{ Distant metastasis-free survival } \\
\hline Factors & $\overline{\mathrm{HR}}$ & $95 \% \mathrm{CI}$ & $P$ value \\
\hline Sex & 3.06 & $0.37-25.17$ & 0.298 \\
\hline Age & 1.67 & $0.48-5.72$ & 0.418 \\
\hline N stage & 2.46 & $0.71-8.54$ & 0.157 \\
\hline Histological type & 1.06 & $0.26-4.39$ & 0.934 \\
\hline Treatment & 0.46 & $0.12-1.79$ & 0.264 \\
\hline Radiation dose & 0.95 & $0.14-1.76$ & 0.276 \\
\hline Tumor volume & 1.13 & $0.33-3.87$ & 0.847 \\
\hline Number of CN palsy symptom & 3.14 & 0.92-10.65 & 0.067 \\
\hline \multicolumn{4}{|c|}{ Locoregional recurrence-free survival } \\
\hline Factors & $\overline{\mathrm{HR}}$ & $\overline{95 \% \mathrm{CI}}$ & $P$ value \\
\hline Sex & 1.61 & 0.17-15.17 & 0.675 \\
\hline Age & 0.89 & $0.16-4.94$ & 0.89 \\
\hline $\mathrm{N}$ stage & 1.49 & $0.28-7.87$ & 0.634 \\
\hline Histological type & 2.16 & $0.36-13.11$ & 0.401 \\
\hline Treatment & 0.76 & $0.12-4.64$ & 0.767 \\
\hline Radiation dose & 2.14 & $0.38-11.94$ & 0.388 \\
\hline Tumor volume & 3.04 & $0.48-19.28$ & 0.238 \\
\hline Number of CN palsy symptom & 4.31 & $0.78-23.82$ & 0.094 \\
\hline
\end{tabular}

*,p $\square 0.05$; CN, cranial nerve; HR, hazard ratio; 95\%CI, 95\% confidence interval 

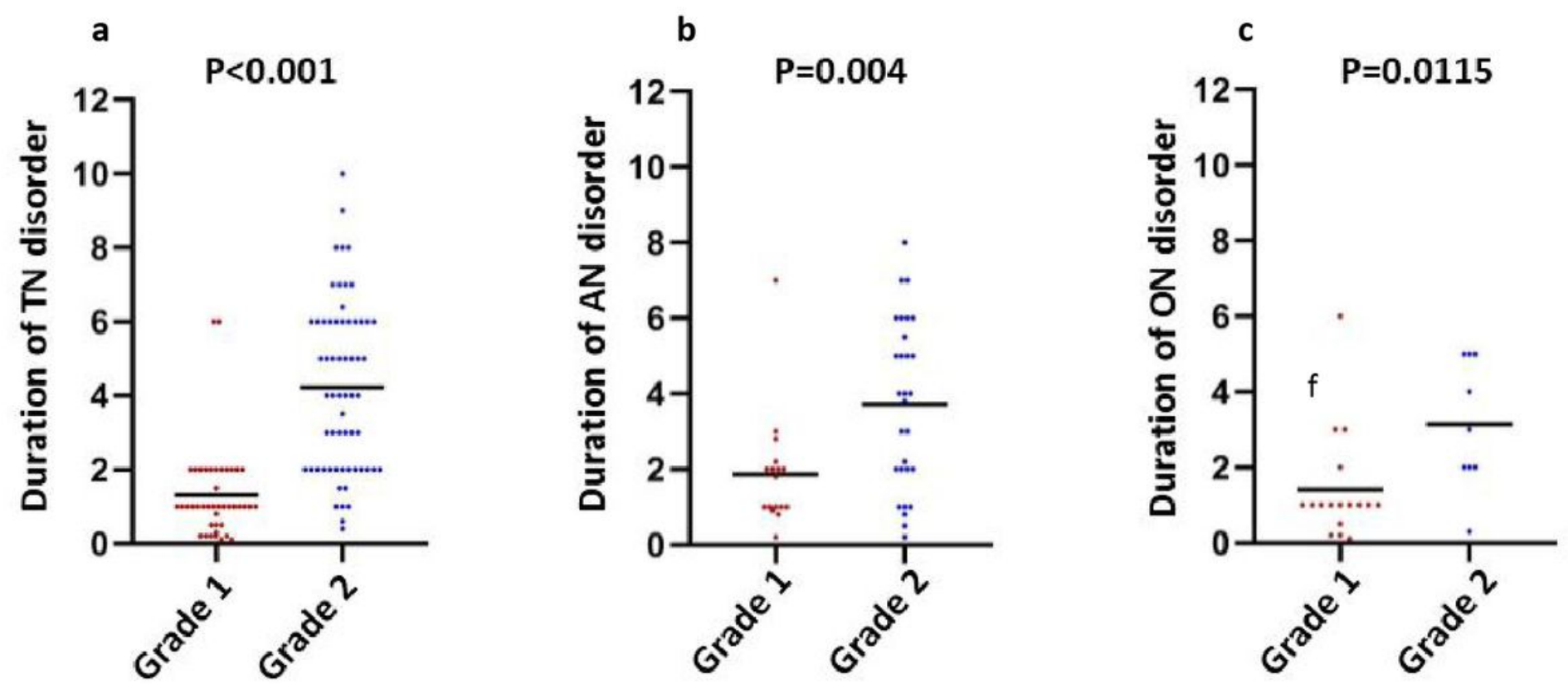

Figure 1

correlation between grade and symptom duration of cranial palsy. TN, trigeminal nerve(a); AN, abducens nerve(b); ON, oculomotor nerve(c).

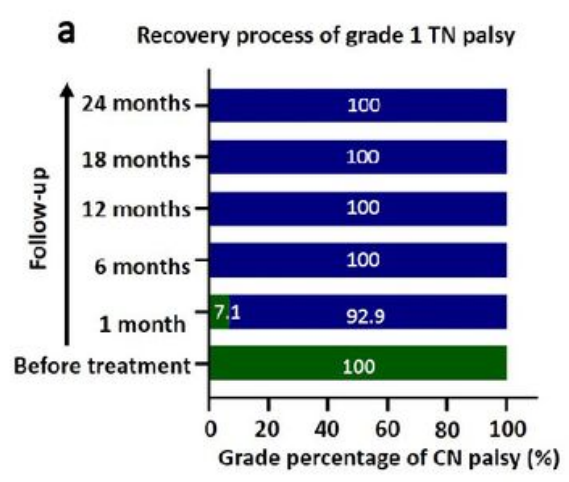

b Recovery process of grade $1 \mathrm{AN}$ palsy
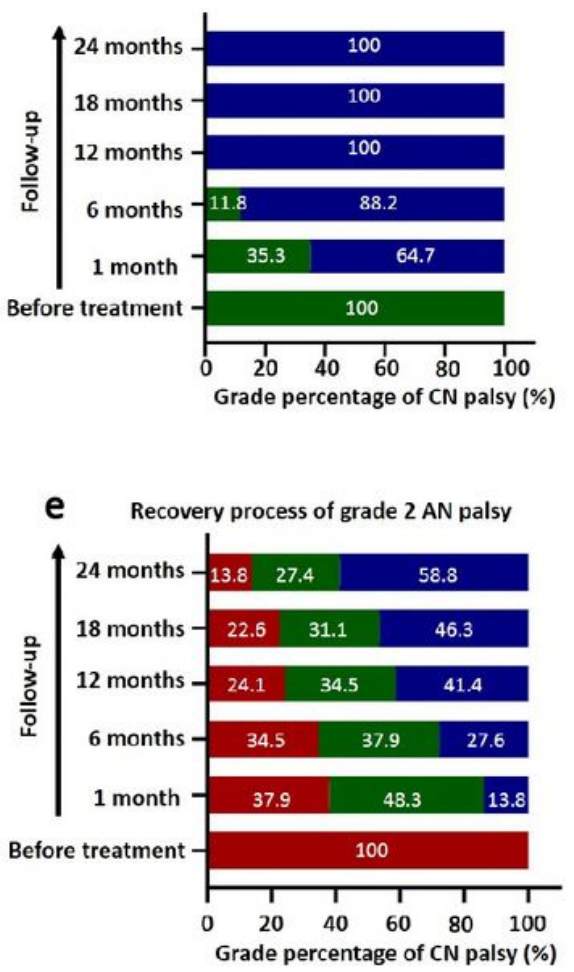

C Recovery process of grade $1 \mathrm{ON}$ palsy
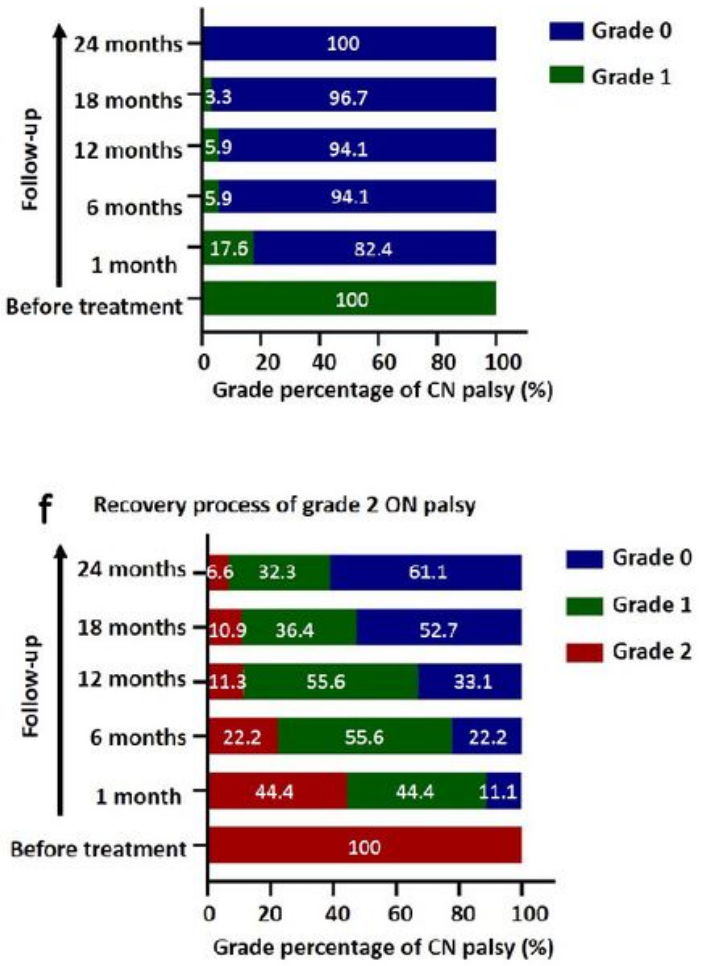

Figure 2

grade changing of cranial palsy after completion of treatment. TN, trigeminal nerve(a,d); $A N$, abducens nerve(b,e); ON, oculomotor nerve(c,f). 
a

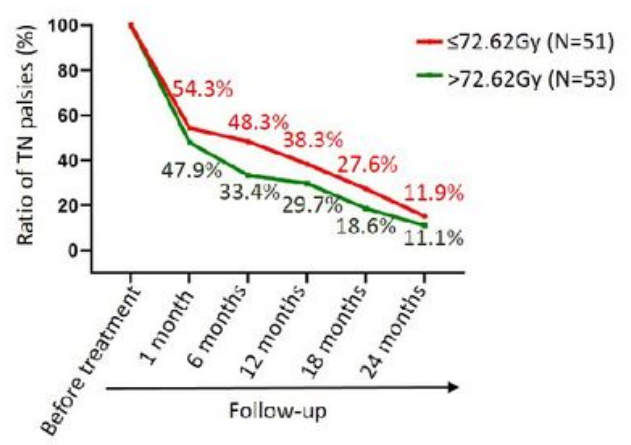

d

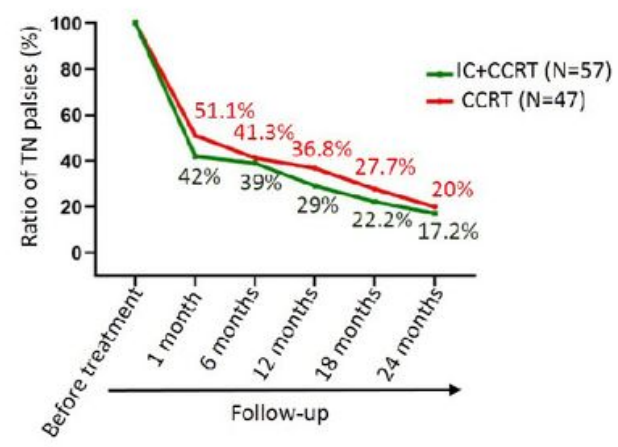

b

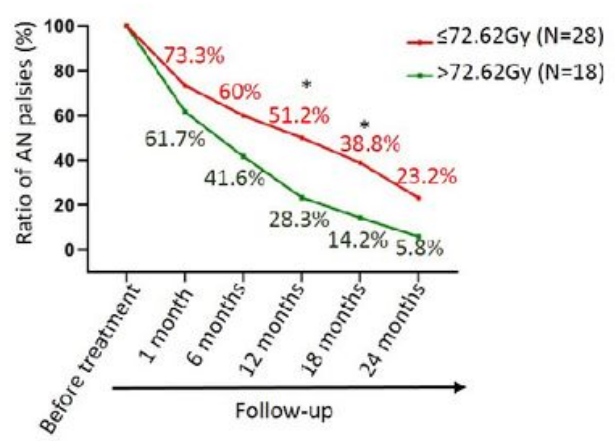

e

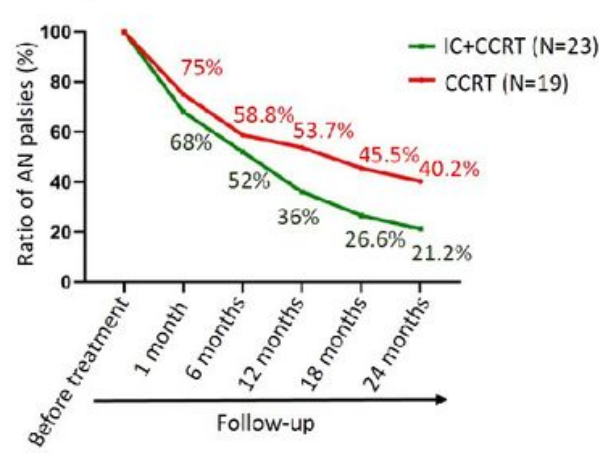

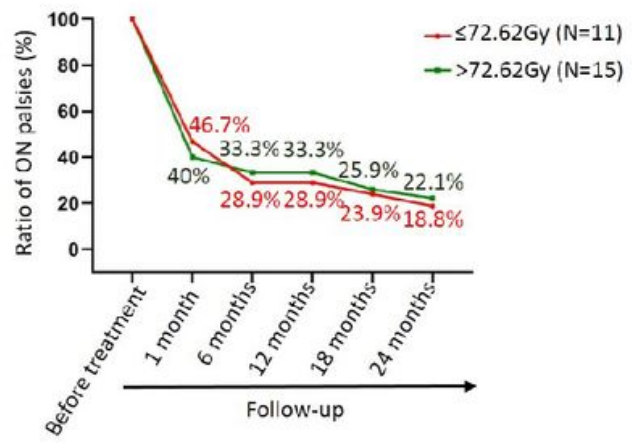

C

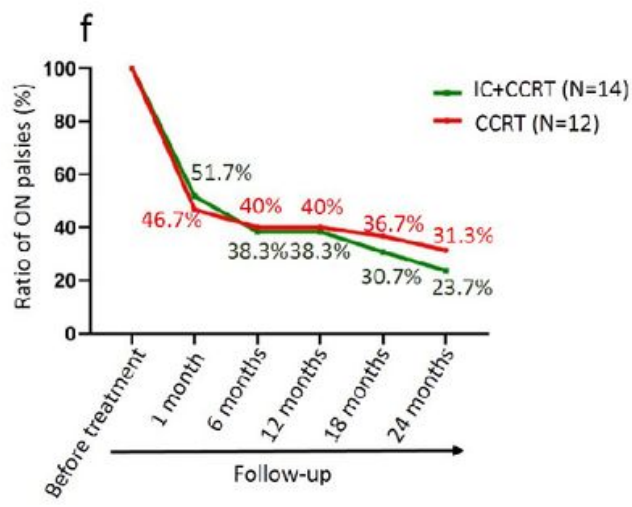

\section{Figure 3}

impact of treatment-related factors on recovery of cranial nerve palsy. a-c, impact of radiation dose on recovery of cranial nerve palsy. Median radiation dose was used as dichotomy; $d$-f, impact of treatment modalites on recovery of cranial nerve palsy. TN, trigeminal nerve; $\mathrm{AN}$, abducens nerve; $\mathrm{ON}$, oculomotor nerve. 

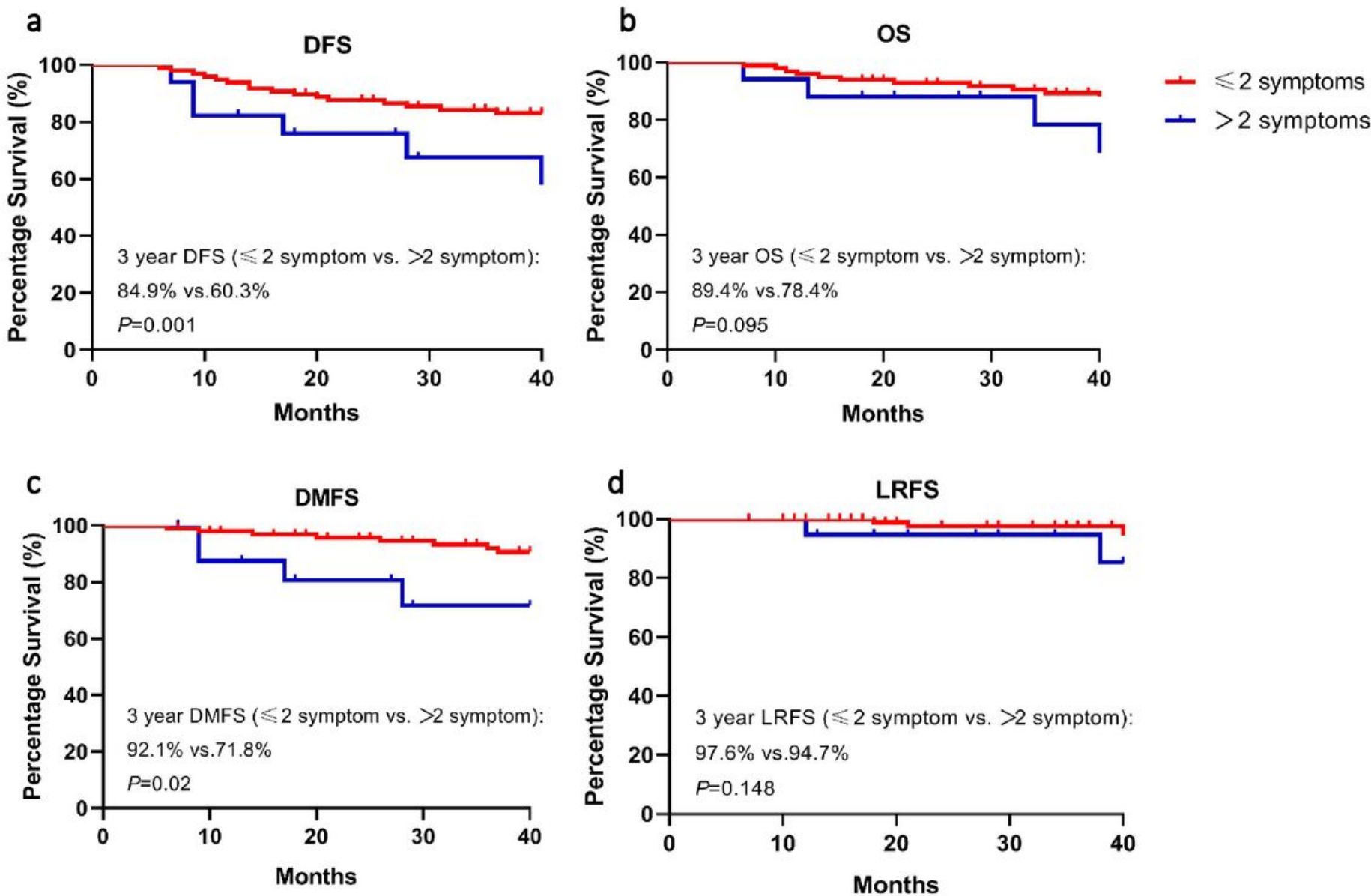

\section{Figure 4}

survival analysis between patients with 1 or 2 symptoms of cranial palsy and patients with more than 2 symptoms of cranial palsy. DFS(a), disease-free survial; OS(b), overall survival; DMFS(c), distant metastasis-free survival; LRFS, locoregional recurrence-free survival(d).

\section{Supplementary Files}

This is a list of supplementary files associated with this preprint. Click to download.

- Fig.S1.jpg

- Fig.S2.jpg

- Fig.S3.jpg

- Fig.S4.jpg

- Fig.S5.jpg

- Fig.s6.jpg 